\title{
NETWORK AND E-COMMERCE NET GENERATION: VLOGGING
}

\author{
Rahmawati Zulfiningrum ${ }^{1}$ dan Amida Yusriana ${ }^{2}$ \\ Institut Pertanian Bogor dan Universitas Dian Nuswantoro, Semarang
}

\begin{abstract}
E-commerce transactions by utilizing a variety of marketplace platform through the In ternet media increasingly in demand by the people in Indonesia. Vlogs are social networks hosted by Net Gener where they can share information, expand communication networks and establish an $N$ fluence network. Vlog as the development of the blog with its a udio-visual capabilities make the voice of the consumer becomes more expressive. Vlogging is much more $N$-fluencial because the information reviews from a vlogger are much more appealing to Followers and viewers than reviews of unknown experts. This research discusses the development of vlog and its utilization for e-commerce (virtual market) through communications network in Net Gener era, along with the increasing of vlogging trend where consumer purchase decision is quickly influenced by $N$-fluence network through social media. The result is that vlogging networks can be an important option for e-commerce producers to promote products and build relationships with their consumers, the NetGener.for e-commerce companies who were capable of viewing opportunities, vlog is the latest innovations.
\end{abstract}

Keywor ds: net gener, vlogging network, e-commerce

\begin{abstract}
ABSTRAK
Transaksi e-commerce dengan memanfaatkan beragam marketplace platform melalui media internet semakin diminati oleh masyarakat di Indonesia. Vlog merupakan jaringan sosial yang digawangi oleh Net Gener untuk saling berbagi informasi, memperluas jaringan komunikasi dan membentuk jaringan $N$-fluence. Vlog sebagai perkembangan dari blog dengan kemampuan audio visual membuat suara konsumen menjadi lebih ekspresif. Vlogging lebih $N$-fluencial karena ulasan informasi dari vlogger jauh lebih menarik bagi followers dan viewers dibandingkan ulasan dari pakar yang tidak dikenal. Penelitian ini membahas mengenai perkembangan vlog dan pemanfaatannya bagi e-commerce melalui jaringan komunikasi pada era Net Gener, seiring dengan meningkatnya tren vlogging dimana keputusan pembelian konsumen dengan cepat turut dipengaruhi oleh jaringan $N$-fluence melalui media sosial. Hasilnya adalah vlogging network dapat menjadi salah satu pilihan penting bagi para produsen e-commerce untuk promosi produk dan menjalin hubungan dengan konsumen mereka yaitu para Net-Gener. Bagi perusahaan e-commerce yang mampu melihat peluang, vlog merupakan inovasi yang terkini.
\end{abstract}

Kata kunci: net gener, vlogging network, e-commerce

\footnotetext{
${ }^{1}$ Rahmawati Zulfiningrum.Email:darumzulfie@gmail.com

2 Amida Yusriani. Email:amidayusriani88@gmail.com
} 


\section{PENDAHULUAN}

\begin{abstract}
Filsuf sosial dari Auguste Comte sampai David Hume menganggap hubungan mendasar antara suksesi generasi biologis dan perubahan dalam masyarakat memiliki sebuah keterkaitan. Pada tahun 1920-an, sosiolog Jerman Karl Mannheim menulis sebuah risalah berjudul "Masalah Generasi" yang menyatakan bahwa analisa terkait generasi memiliki kandungan formasi pengalaman yang sangat penting, dan dapat memberikan gambaran unik tentang kerangka acuan yang dapat menjadi kekuatan yang sangat kuat dalam kehidupan di masyarakat mendatang (Alwin \& McCammon, 2003).
\end{abstract}

Thomas L Friedman salah seorang kolumnis New York Times mengilustrasikan dunia digital melalui pemikirannya bahwa "Saat ini dunia sudah sangat terhubung menjadi satu, yang membuat anda tidak hanya melihat sebatas dari tempat anda berdiri seperti dimana karavan itu dan seberapa jauh atau tertinggalnya anda". Di masa lalu, teknologi informasi dan komunikasi tersegmentasi ke dalam tingkat ekonomi dan sistem teknik yang terpisah dengan kemampuan minimal untuk melalukan "interoperabilitas" yaitu kapabilitas dari suatu produk atau sistem yang dapat diungkapkan sepenuhnya untuk berinteraksi dan berfungsi dengan produk lain, kini atau di masa mendatang, tanpa adanya batasan akses atau implementasi (Tham, 2014).

Pembagian generasi terbagi kedalam lima bagian, yaitu Generasi silent yang lahir pada tahun 19251946, Generasi baby boom yang lahir pada tahun 1947-1964, Generasi X yang lahir pada tahun 1965-1979, Generasi Milenial atau Generasi Y yang lahir pada tahun 1980-1999, serta generasi $\mathrm{Z}$ yang lahir mulai tahun 2000. Generasi Y ialah kelompok generasi yang berusia 34 tahun ke bawah atau yang lahir pada periode tahun 80-an hingga 90-an. Generasi yang sudah sangat akrab dengan internet dan media sosial ini tidak takut dengan perubahan, namun sering juga disebut tidak sabar dalam melalui proses untuk menuju ke perubahan itu sendiri. Karakteristik Generasi $Y$ ini sangat unik karena mereka sudah tumbuh di tengah hiruk pikuk teknologi nirkabel yang sedang berkembang. Generasi ini juga sering dikatakan sebagai angkatan kerja yang produktif, penuh kejutan dan ide brilian, serta generasi masa depan yang handal.

Bolton et al. (2012) dalam Understanding Generation $Y$ and Their Use of Social Media: A Review and Research Agenda mengemukakan bahwa Generasi Y atau Generasi Milenium memberikan daya tarik tersendiri bila dilihat dari 
dua sudut pandang yaitu seorang manajer dan akademisi. Dalam hal yang umum, Generasi Y disebut sebagai digital native, bukan digital imigrant (Prensky, 2001). Mereka adalah generasi pertama yang telah menghabiskan seluruh hidup mereka di lingkungan digital, teknologi informasi secara mendalam telah mempengaruhi bagaimana mereka hidup dan bekerja.

Perubahan sosial yang dihadirkan oleh generasi $\mathrm{Y}$ ini diantaranya dapat kita lihat melalui contoh yang dilakukan oleh Muhammad Alfatih Timur yang berusia 24 tahun. Ia melakukan penggalangan dana sosial melalui platform Kitabisa.com, salah satunya adalah penggalangan donasi "Perahu untuk Pak Guru" di Pulau Pura Kabupaten Alor Nusa Tenggara Timur. Alfatih berhasil mengumpulkan dana bagi seorang guru yang setiap harinya harus berenang mengarungi lautan untuk dapat mengajar, dengan tangan satunya menjunjung tas berisi peralatan kerja yang dibungkus plastik, dan setiap berenang ia harus terus menjaganya agar tidak basah. Kesuksesan penggalangan dana secara massal yang di gawangi oleh Kitabisa.com, menjadikan sebuah inspirasi bagi generasi $\mathrm{Y}$ yang lain, bahwa Generasi Y juga dapat secara aktif memberikan kontribusi, berbagi, mencari dan mengkonsumsi konten plus karya atau prosumer dimana creation dan consumption saling berkombinasi. Prosumer exchange dapat terjadi selama audiens terkoneksi via beberapa platform. Prosumer sama dengan produsage, audiens bisa merangkap menjadi produsen sekaligus konsumen media dan sekaligus bermain di platform media sosial melalui dunia maya (Tham, 2014).

Vlog menurut Urban

Dictionary adalah sebuah video dokumentasi jurnalistik yang berada di dalam web yang berisi tentang kehidupan, pemikiran, opini, dan ketertarikan. Vlog dapat juga dibuat dengan peralatan sederhana dengan memanfaatkan kecanggihan kamera smartphone, vlog berbeda dengan blog karena para vlogger harus memiliki kemampuan untuk berbicara di depan kamera dan membuat videonya agar menarik bagi audiens.

Blog video (vlogs) adalah genre computer-mediated communication (CMC), menampilkan pembicara tunggal yang berbicara di hadapan kamera, menggunakan elemen multimodal yang secara teratur menjadi bagian dari interaksi lisan, di iringi dengan perubahan tatapan, posisi tubuh, ekspresi wajah, kualitas suara dan nada. Cuplikan video dalam vlog dapat ditonton oleh masyarakat umum setelah diunggah ke platform video secara online, misalnya YouTube, audiens dapat 
meninggalkan komentar tertulis atau tanggapan terhadap vlog. Produk ini merupakan monolog asynchronous, dimediasi yang disesuaikan dengan khalayak yang tidak hadir sebagai audiens secara langsung (Frobenius, 2014).

Suatu jaringan dalam Sosiologi lazim dikonsepsikan sebagai suatu tipe hubungan antar aktor yang ditandai oleh bentuk interaksi timbal balik yang simetris. Setiap hubungan antar aktor yang terjalin dalam masyakarat adalah suatu bentuk jaringan (the building block network), karena itu dasar hubungan sosial yang berbeda akan melahirkan jaringan yang berbeda pula. Menurut Rogers dan Kincaid (1981) dalam menjalin hubungan sosial, setiap aktor membawa ciri-ciri kepribadiannya sendiri sehingga konfigurasi masuknya atau keluarnya seorang aktor dalam jalinan hubungan sosial akan mempengaruhi struktur interaksi yang diciptakan. Tren vlogging salah satunya menyebar melalui jaringan komunikasi.

Penulisan ini akan membahas mengenai perkembangan vlog dan pemanfaatannya bagi e-commerce (pasar virtual) melalui jaringan komunikasi pada era Net Gener, seiring dengan meningkatnya tren vlogging di mana keputusan pembelian konsumen dengan cepat turut dipengaruhi oleh jaringan $N$ Fluence melalui media sosial. Untuk menguraikan bagaimana vlogging network mampu menghadirkan pola interaksi yang berbeda dalam virtual marketplace bagi para Net Gener yang tidak hanya menjadi konsumen tapi juga prosumer.

\section{METODE PENELITIAN}

Penelitian menggunakan pendekatan deskriptif kualitatif. Data penelitian diperoleh melalui studi literatur (desk study), dari berbagai buku-buku, jurnal-jurnal dan informasi melalui internet. Tahap selanjutnya dari data-data yang diperoleh dianalisis dengan 6 derajat pengukuran indikator terhadap jaringan meliputi: 1) koneksi (connectedness), 2) keterjangkauan (reachability), 3) resiprositas (reciprocity), (4) kepadatan (density), 5) sentralitas (centrality), 6) kebersamaan (betweeness) untuk mengetahui hubungan antara vlogger terhadap jaringannya. Penelitian ini juga melakukan analisis berkaitan dengan situasi e-commerce yang ada di Indonesia

\section{HASIL DAN PEMBAHASAN Vlog dan Jaringan N-Fluence Di Era Net Gener}

Vlog merupakan jaringan sosial yang digawangi oleh Net Gener di mana mereka dapat saling berbagi informasi. Vlog semakin memperluas jaringan komunikasi dengan jalinan antara vloggers dan audiensnya yang akhirnya 
membentuk sebuah jaringan $N$ fluence (para konsumen saling mengulas dan mempengaruhi). Followers (pengikut) vloggers akan memantau terus apa kegiatan vloggers dan produk apa yang direviewnya. Vloggers menggunakan jaringan-jaringan komunikasi dengan ukuran yang jauh lebih besar, jauh lebih kompleks dan efisien.

Vloggers membuat konteks percakapan satu sama lain melalui situs YouTube. Vloggers menggunakan mode komunikatif yang berbeda untuk menjalin kontak mata, bergiliran dalam percakapan, berbagi isyarat yang mengandung pesan, berbagi pemahaman dan menegosiasikan khalayak secara simultan. Terlepas dari perasaan yang terputus karena tidak melakukan komunikasi secara langsung dan potensi munculnya pemaknaan yang ambigu, vlogging dapat memfasilitasi konteks percakapan dimana kesamaan minat dibagi melalui adanya kontak sosial dan komunikasi integratif dapat terjadi (Harley, 2009).

Jaringan sosial sangat mempengaruhi kebiasaan berbelanja Net Gener melalui e-commerce. Kekuatan virtual memusatkan perhatian dalam hal dominasi dari produsen yang bergeser kepada konsumen. Agar dapat bersaing di marketplace, perusahaan perlu melakukan diferensiasi produknya, memberikan pelayanan terbaik, dan harga yang terjangkau. Vlog sebagai perkembangan dari blog dengan kemampuannya yang audio visual membuat suara konsumen menjadi lebih ekspresif. Bagi perusahaan $e$ commerce yang mampu melihat peluang, vlog merupakan inovasi yang kekinian.

Tapscot mengemukakan bahwa komunitas blogging atau yang saat ini dikenal dengan vlogging lebih $N$-fluencial daripada ulasan dari pakar-pakar ternama sekalipun. Ciri dasar blog atau vlog seperti konten percakapan, memungkinkan konten dan pandangan-pandangan yang bagus muncul berdasarkan pada kemanfaatan. Ulasan informasi dari seorang vlogger jauh lebih menarik bagi Followers-nya dibandingkan ulasan dari pakar yang tidak dikenal oleh Net Gener. Saat ini perusahaan harus mampu untuk mengidentifikasi dan melibatkan suara-suara otoritas yang baru seperti para vlogger dengan cara membuat kategori bidang para vloggers, sebagai contoh apakah vlogger bidang kecantikan, vlogger Traveller, vlogger kuliner dan lain sebagainya. 


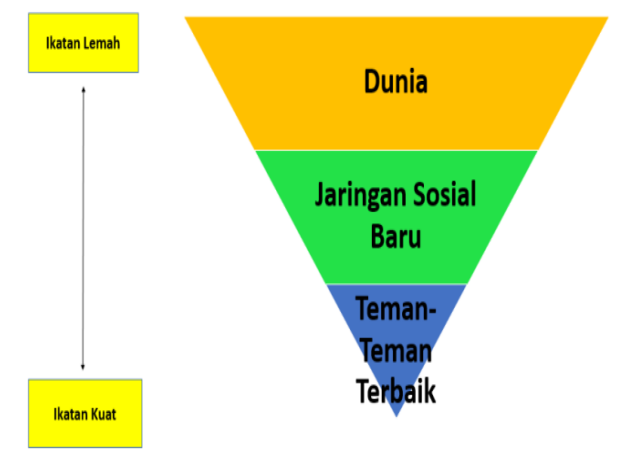

Gambar 1. Tiga Kategori Jaringan $N$-fluence

Sumber: The Net Generation:"A Strategic Investigation, nGenera, 2008”

Net Gener adalah konsumen dengan jenis yang baru dalam dunia yang baru juga yaitu virtual marketplace. Net Gener membuat para praktisi pemasaran menulis ulang aturanaturan pemasaran, dimana perusahaan tidak lagi memonopoli proses penciptaan produk, menetapkan harga, memilih tempat, promosi produk dan mengendalikan pesan. Prinsip empat $\mathrm{P}$ (product, price, place, dan promotion) dalam pemasaran yang efektif, dengan menciptakan produk, menentukan ciri-ciri serta manfaatnya, menetapkan harga, memilih tempat untuk menjual produk dan jasa, promosi secara gencar melalui iklan, public relation, penawaran langsung melalui direct mail di era Net Gener sudah lebih dinamis. Situasi telah berubah, konsumen tidak lagi dianggap pasif, dan produsen bukan lagi seseorang yang sangat berkuasa dalam mengendalikan pesan produk.
Saat ini perusahaanperusahaan di era virtual menurut Tapscot menerapkan prinsip pemasaran ABCDE yaitu; Anyplace (Net Gener dapat membeli produk yang dinginkannya dimanapun dan kapanpun), Brand (Net Gener turut membantu dalam membentuk merk dan produk), Communication (iklan yang mainstream akan tergantikan dengan pola komunikasi dua arah dan interaktif di mana integritas perodusen merupakan poin penting), Discovery (proses penemuan harga karena sebelum membeli suatu produk Net Gener akan meneliti baik produk maupun harganya melaui media online, dan Net Gener akan membandingkan harga hingga mendapatkan yang sesuai dengan keinginan mereka), dan Experience (sebuah produk diharapkan dapat memberikan pengalaman baru bagi Net Gener.

Vlog dan 8 Norma Net Generation 
Net Generation menurut

Tapscot (2013) mengerjakan sesuatu yang menakjubkan dengan teknologi yang menerapkan delapan norma dalam berbelanja yaitu;

Kebebasan (Net Gener menginginkan pilihan yang beragam dan kebebasan dalam memilih produk), (2) Kustomisasi (Net Gener menyukai produk yang dimilikinya "exclusive" dengan cara menyesuaikan produk baru yang ditawarkan sesuai keinginannya), (3) Penyelidikan (Net Gener memanfaatkan media online untuk meneliti suatu produk, baik dari sisi harga maupun perbandingan dengan produk lain sebelum berbelanja secara online maupun offline di toko konvensional, (4) Integritas (Net Gener mengharapkan perusahaan untuk bekerja dengan integritas, dapat memenuhi harapan konsumen dan bertanggungjawab terhadap produk dan pelayanan konsumen, (5) Kolaborasi (Net Gener menginginkan adanya kerjasama dengan perusahaan untuk menciptakan produk dan jasa yang lebih baik), (6) Hiburan (Net Gener menyukai untuk menjadikan produk sebagai sesuatu yang menyenangkan tidak hanya dilihat dari fungsinya, (7) Kecepatan (Net Gener mengharapkan kecepatan perusahaan ketika berinteraksi dan menanggapi permintaan mereka, dan (8) Inovasi (Net Gener menginginkan produkproduk yang tersedia merupakan produk paling baru dan paling bagus untuk mereka, dan ketika mereka memilikinya lebih dulu dari Net Gener yang lain maka akan menaikkan status sosial mereka dan membuat iri yang lain.

Delapan norma ini berawal dari konsumsi media yang berbeda dari Net Gener sehingga menghasilkan pengalaman yang berbeda. Net gener terbentuk menjadi seorang aktor, pemrakarsa, pencipta, pemain, dan sekaligus sebagai seorang kolaborator. Kehadiran internet membuat Net Gener menjadi diri mereka sendiri dan sangat berbeda dengan yang terjadi pada generasi baby boomer di masa muda. Internet jika dimanfaatkan dengan bijak memiliki beragam manfaat yang positif.

Kaitan dengan poin integritas, Net Gener merupakan generasi yang tidak suka dan tidak mudah untuk dibodohi, sebagai contoh yang diungkapkan Stiggants (2015) dimana Followers atau viewers memberikan komplain terhadap dua orang vlogger populer yang melakukan promosi berbayar dari salah satu produsen produk makanan ringan namun tidak mencantumkan keterangan bahwa itu adalah bagian dari kegiatan promosi yaitu dengan penambahan keterangan kode promo "\#promo". Bagi Followers dari seorang vlogger sangat penting untuk membedakan apakah itu konten promosi atau natural. Produsen atau 
perusahaan dapat bekerjasama dengan para vlogger untuk dapat membangun percakapan dengan konsumen, namun vlogger juga harus tetap dapat mempertahankan keseimbangan konten karena mereka memiliki hubungan yang "organik" dengan Followers dan hal itu dapat terganggu bila terlalu banyak konten advertorial dalam vlog-nya karena integritas vlogger juga hal yang penting untuk dipertahankan. Net Gener juga menginginkan kesempatan untuk berbicara atau keterlibatan dengan perusahaan atau para produsen.

\section{Vlogging Network dan $E$ - Commerce di Indonesia}

Vlog saat ini semakin dimanfaatkan untuk promosi digital marketing e-commerce. Video blog atau yang lazim disingkat vlog adalah sebuah blog yang menggunakan video sebagai media, vlogger adalah sebutan bagi orang yang membuat vlog. Istilah para vlogger yang membuat vlog disebut vlogging. Vlogging biasanya dilakukan dengan berbicara di di depan kamera dan berbagi beragam informasi. Zoella Sugg adalah salah satu vlogger populer dari UK yang muncul dari YouTube. Pengguna YouTube beramai-ramai membuat vlog dan beberapa telah mengumpulkan sejumlah besar viewers, dengan beberapa vlogger memiliki lebih dari 100 juta pelanggan. Vloggers mengunggah video tentang produk yang mereka gunakan atau kehidupan pribadi mereka, sehingga meningkatkan lalu lintas dari pemirsa pelanggan dan anonim. Akibatnya, vloggers menjadi apa yang disebut sebagai selebriti YouTube. Kemunculan vlog dan kesuksesan "selebriti YouTube" telah menyediakan merk dengan alat marketing untuk terhubung dengan konsumen (Lee, 2016).

Dredge

mengemukakan hasil dari survei terhadap 1.500 anak berusia 13-17 tahun di AS yang ditugaskan oleh Variety pada tahun 2014 bahwa "YouTube stars scored significantly higher than traditional celebrities across a range of characteristics considered to have the highest correlation to influencing purchases among teens". Beberapa vloggers terbukti memiliki pengaruh dalam meyakinkan penggemar untuk membeli produk yang mereka ulas. Vlogger Zoella's Girl Online bahkan mendulang sukses dengan penjualan buku tercepatnya sebagai seorang vlogger dan ini merupakan impact dari jaringan Followers dan viewersnya yang cukup besar di Inggris pada tahun 2014. 


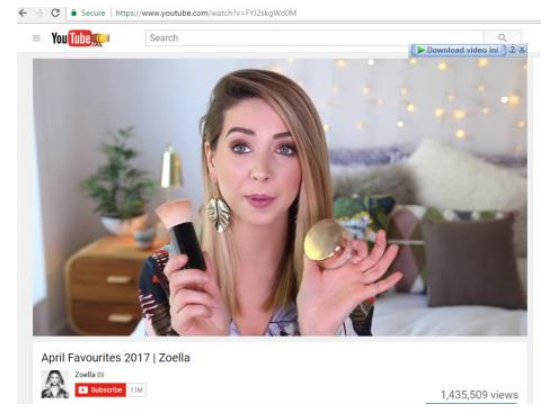

Gambar 2. Vlogger Zoella Sugg

Sumber:

YouTube

Di Indonesia tren vlog mulai muncul sejak tahun 2005, berdasarkan data dari Wolipop vlogger di Indonesia sebagian besar masih didominasi oleh perempuan dengan spesifikasi sebagai beauty vlogger, mereka mengunggah seputar tutorial make-up, tips-tips make-up, tutorial hijab, fashion, gaya hidup, travelling dan lain sebagainya. Abel Cantika adalah salah satu yang populer sebagai beauty vlogger atau vlogger kecantikan. Vlogger dengan jumlah subscriber mencapai lebih dari 128 ribu itu sudah sejak 2015 aktif mengunggah tips-tips make-up di akunnya. Salah satu video Abel yang paling populer adalah saat berdandan menggunakan make-up yang harga total keseluruhan produknya hanya Rp 200 ribu (Wolipop, 2017).

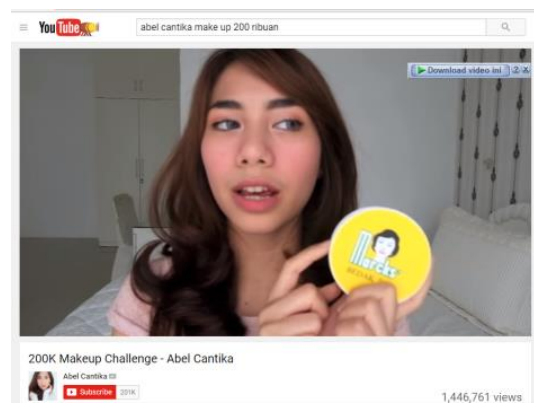

Gambar 3. Vlogger Abel Cantika

Sumber:

YouTube

Para beauty vlogger dapat menjadi $N$-fluence yang potensial bagi industri kosmetik. Dengan popularitas mereka di kalangan $\mathrm{Net}$ Gener yang menjadi Followers-nya. Terlebih informasi yang disampaikan para vlogger dapat mewakili rasa keingintahuan konsumen pada umumnya. Sari (2016) mengemukakan bahwa salah satu brand kosmetik lokal di Indonesia Polka merupakan salah satu pebisnis kosmetik online lokal yang mengandalkan media digital sebagai platform utama bisnisnya menerapkan strategi ini untuk mempromosikan produknya pada $\mathrm{Net}$ Gener perempuan. Dengan cara memperkenalkan brand kosmetiknya kepada beberapa beauty vlogger dengan harapan mereka dapat memberikan ulasan yang tulus dari produk Polka di vlog-nya, baik positif atau negatif dengan misi untuk menjadikan produknya semakin "high-end yang berkualitas". 


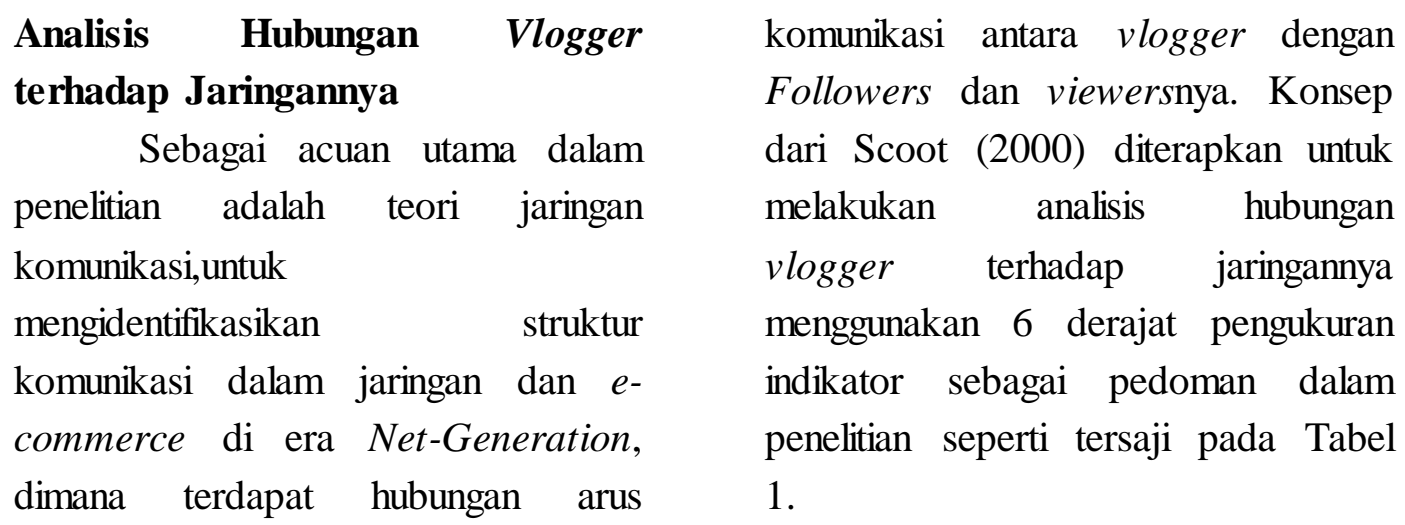

Tabel 1. Analis is Hubungan Vlogger Terhadap Jaringannya

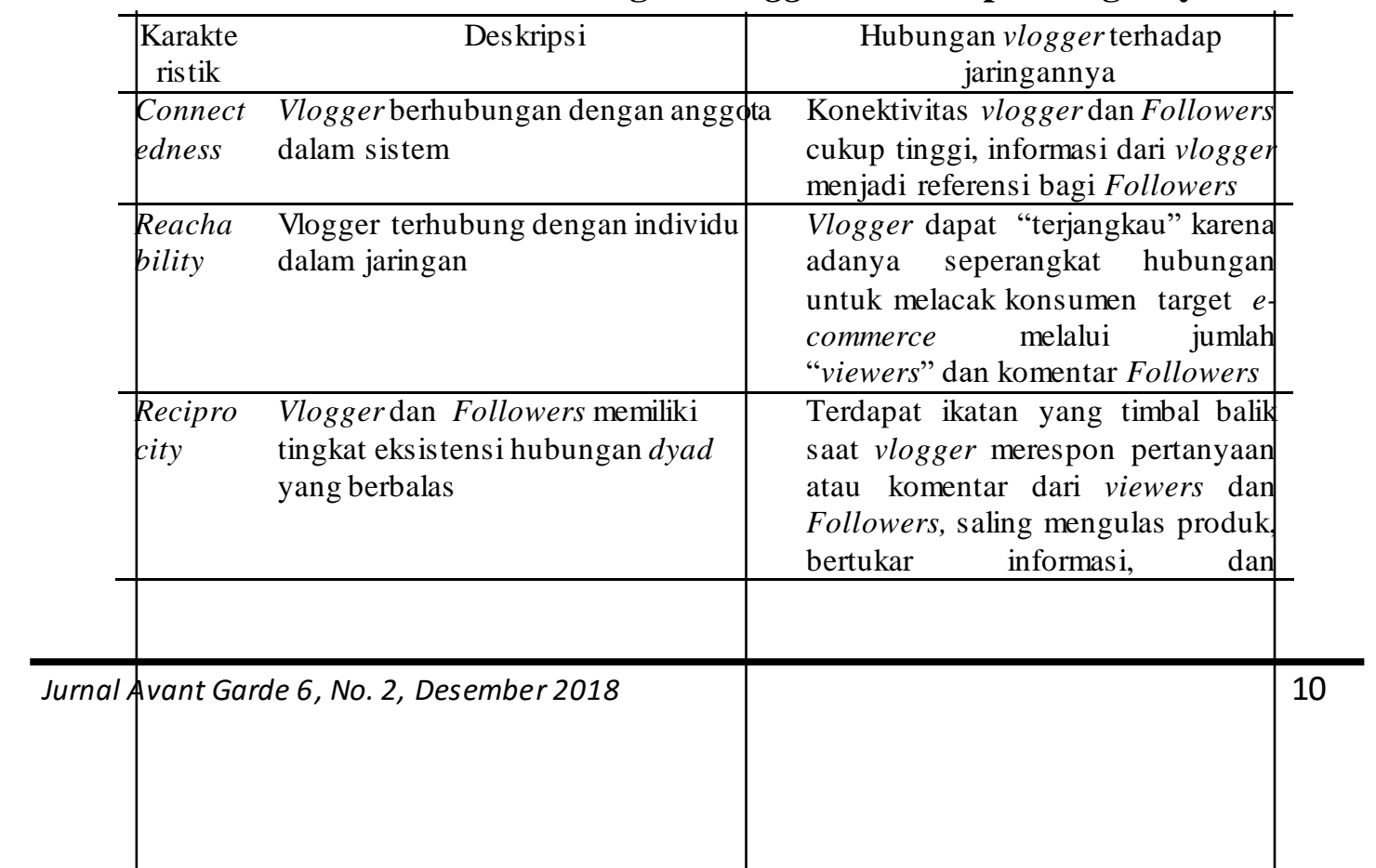




\begin{tabular}{|c|c|c|}
\hline & & mempengaruhi \\
\hline Density & $\begin{array}{l}\text { Kepadatan jaringan antara vlogger } \\
\text { dan Followers }\end{array}$ & $\begin{array}{l}\text { Dapat memberikan wawasan dan } \\
\text { informasi dalam tren pemanfaatan } \\
\text { vlogging bagi e-commerce, melalui } \\
\text { difusi informasi }\end{array}$ \\
\hline $\begin{array}{l}\text { Centrali } \\
\text { ty }\end{array}$ & $\begin{array}{l}\text { Vlogger merupakan "star" dalam } \\
\text { kelompoknya }\end{array}$ & $\begin{array}{l}\text { Vlogger yang menjadi "star" } \\
\text { memiliki hubungan dengan } \\
\text { Followers, meliputi sentralitas lokal } \\
\text { dan global. Tingkat ke populeran } \\
\text { diukur melalui jumlah ikatan yang } \\
\text { dibutuhkan untuk menghubungi } \\
\text { seluruh folowersnya. }\end{array}$ \\
\hline $\begin{array}{l}\text { Betwee } \\
\text { ness }\end{array}$ & $\begin{array}{l}\text { Followers memiliki ketergantungan } \\
\text { okal (local dependency) terhadap } \\
\text { logger }\end{array}$ & $\begin{array}{l}\text { Informasi yang diakses Followers } \\
\text { melewati vlogger terlebih dahulu. } \\
\text { Vlogger menjadi "gatekeeper" } \\
\text { dengan mengulas informasi atau } \\
\text { produk "apa adanya" sehingga Net } \\
\text { Gener cenderung lebih percaya. }\end{array}$ \\
\hline
\end{tabular}

Pertama connectedness, vlogger berhubungan dengan anggota-anggota lain dalam sistem. Vlogger dan Followers-nya memiliki konektivitas yang cukup tinggi karena Followers biasanya menjadikan vlogger sebagai acuan atau referensi. Kedua Reachability, vlogger terhubung dengan individu lain dalam jaringan. Seorang vlogger juga dapat dikatakan "terjangkau" karena adanya seperangkat hubungan yang dapat dilacak dari sumber ke individu yang menjadi target melalui jumlah viewers dan komentar dari Followers.

Ketiga reciprocity, vlogger dan Followers-nya memiliki tingkat eksistensi hubungan dyad yang saling berbalas. Para vlogger kerapkali membalas pertanyaan maupun komentar dari viewers dan Followers-nya, sehingga ada ikatan yang timbal balik diantara mereka. Para follower dan viewer juga dapat saling mengulas produk, bertukar informasi dan mempengaruhi. Keempat density, kepadatan jaringan antara vlogger dan Followers-nya dapat memberikan wawasan dan informasi dalam tren pemanfaatan vlogging bagi e-commerce, seperti kecepatan dimana sebuah informasi ulasan produk berdifusi antara individu.

Kelima centrality, vlogger dalam sentralitas merupakan "star" yaitu orang yang "populer" dalam kelompoknya dan menjadi pusat perhatian. Seorang vlogger yang menjadi "star" memiliki sejumlah hubungan yang luas dengan Followers-nya. Vlogger juga memiliki poin yang dapat dianalisa lebih jauh meliputi sentralitas lokal dimana seorang vlogger berhubungan dengan individu lain atau Followers-nya, serta sentralitas global yang memperhatikan keunggulan seorang vlogger dengan 
keseluruhan jaringan. Tingkat kepopuleran vlogger dapat diukur melalui seberapa besar jumlah ikatan yang dibutuhkan seorang vlogger untuk menghubungi seluruh Followers-nya maupun viewers-nya, dengan melihat seberapa besar respon dari Followers atau viewers terhadap suatu ulasan informasi atau produk dari jumlah viewers dan komentar. Jika semakin kecil nilai sentralitas global maka hal tersebut menunjukkan bahwa semakin mudah bagi seorang vlogger untuk menghubungi semua follower dalam jaringannya, sehingga kemampuan vlogger dalam mempersuasi Followers-nya dapat diperkirakan dalam konteks pemasaran produk $e$ commerce agar berjalan dengan efektif dan efisien.

Keenam betweeness, dalam konsep betweeness Followers dalam jaringan vlogging memiliki "local dependency" atau "ketergantungan lokal" terhadap vlogger, hal ini dikarenakan informasi yang diakses oleh Followers-nya melewati individu atau vlogger terlebih dahulu. Vlogger menjadi semacam "gatekeeper" karena mereka mengulas suatu produk "apa adanya" sehingga Net Gener cenderung lebih mempercayai ulasan vlogger, Followers maupun viewers umum dibandingkan ulasan seorang pakar yang tidak dikenalnya.

\section{Analisis Situasi E-Commerce di Indonesia}

Berdasarkan data dari ecommerceiq.asia, untuk mengetahui pemain online terbesar di Indonesia dapat dilihat melalui lalu lintas situs e-commerce dan popularitas aplikasi mereka di Google Play dan Apple Store. Kompetisi untuk merebut pasar terbesar di Asia Tenggara diprediksi pada tahun 2025, akan mendominasi hingga 52 persen dari semua aktivitas e-commerce. Hal ini dapat di amati dari data lalu lintas web e-commerce setiap bulannya dan sepuluh aplikasi belanja ranking teratas di indonesia sebagai berikut;

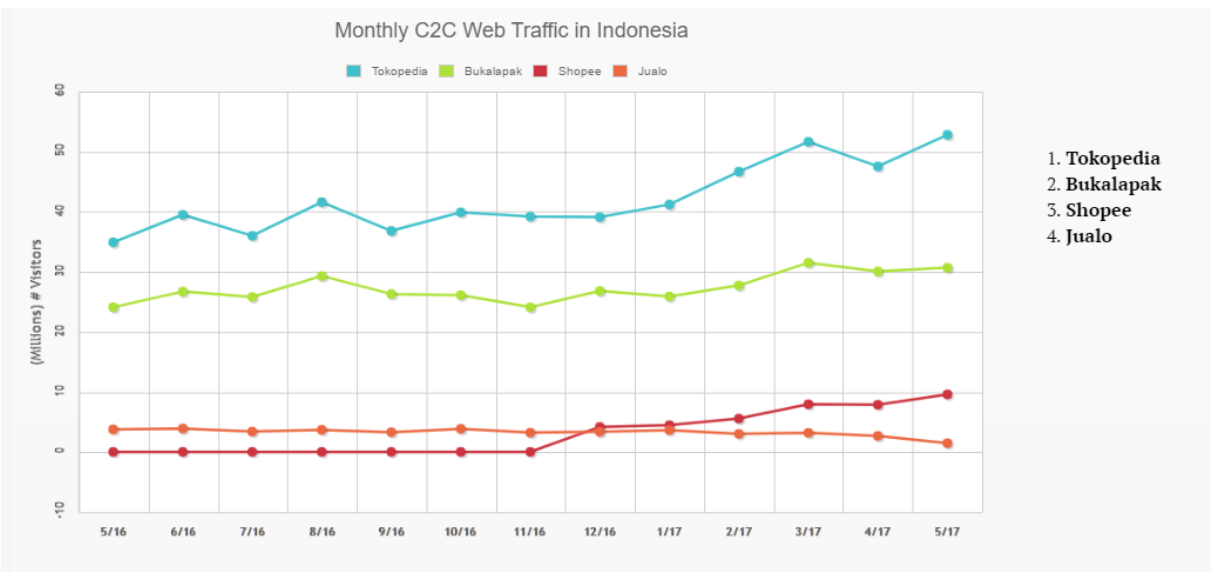

Gambar 4. Monthly E Commerce Web Traffic 


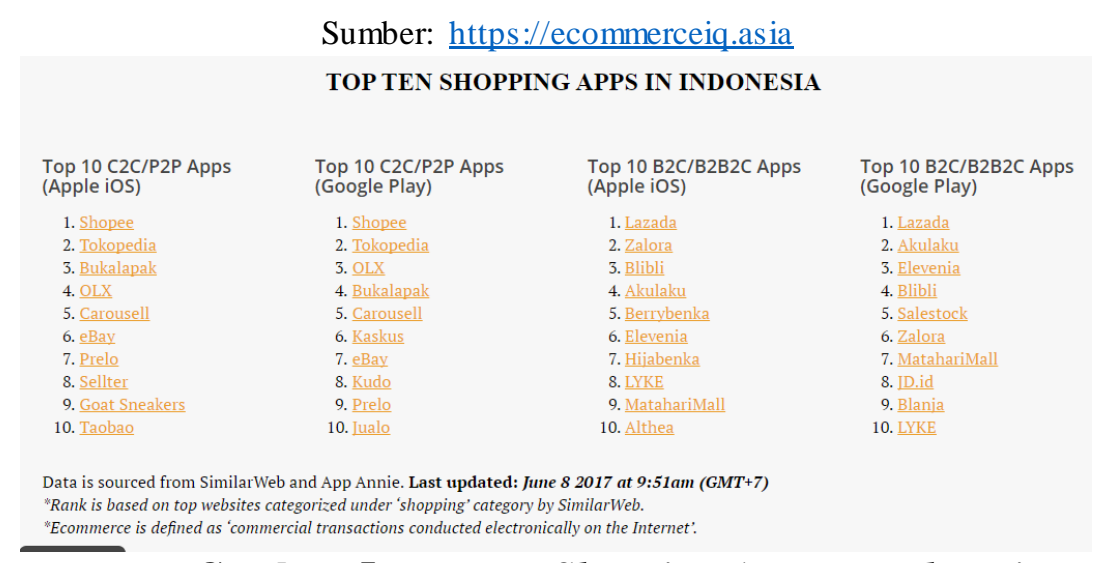

Gambar 5. Top Ten Shopping Apps In Indonesia

Sumber: https://ecommerceiq.asia

Berdasarkan ulasan data Monthly Ecommerce Web Traffic 2017 dapat kita lihat bahwa terdapat 4 pemain besar e-commerce di Indonesia dimulai dari peringkat teratas yaitu Tokopedia, Bukalapak, Shopee dan Jualo. Top Ten Shopping Apps In Indonesia memperlihatkan pada posisi teratas adalah Shopee dan Lazada. Marketplace ini menjadi favorit di Indonesia karena salah satunya mereka dapat memaintenance hubungan mereka dengan baik kepada para Net Gener konsumennya.

\section{Popular Item Purchased Online DailySociali}

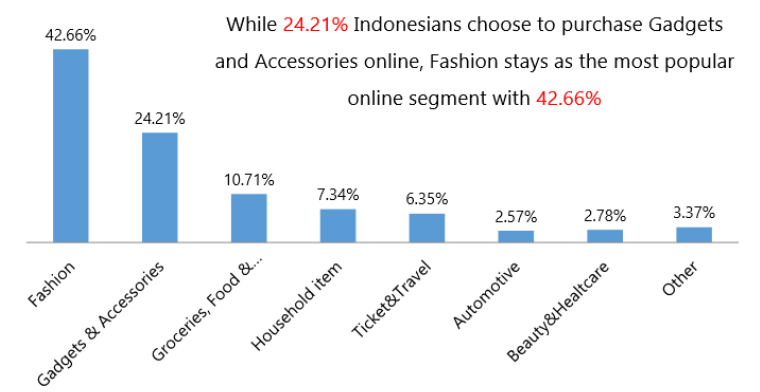

Gambar 6. Popular Item Purchased Online

Sumber: Customer Satisfaction in Indonesia's E-Commerce Services (2016) 
Reasons to Shop Online

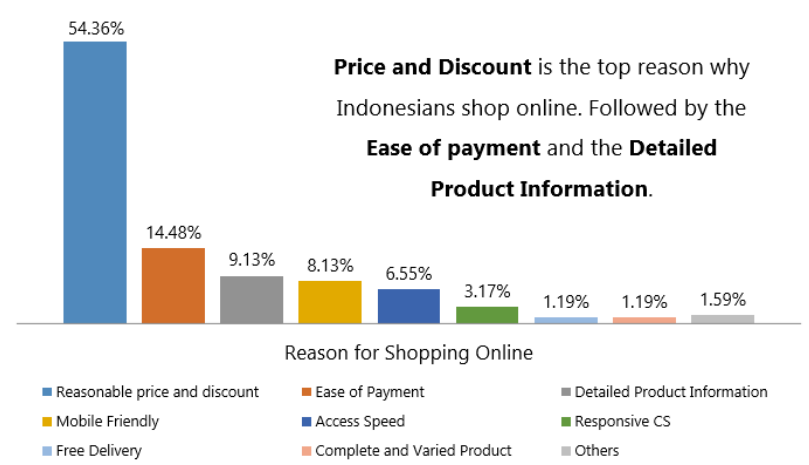

Gambar 7. Top Ten Shopping Apps In Indonesia

Sumber: Customer Satisfaction in Indonesia's E-Commerce Services (2016)

Riset dari ecommerceiq.asia tahun 2014 hingga 2015 mengemukakan bahwa berinvestasi dalam usaha pemasaran digital seperti iklan PPC, kampanye YouTube, dan iklan Google Display memungkinkan merk suatu produk dapat memenuhi keinginan pembeli dan muncul di seluruh web saat mereka melakukan pencarian informasi terhadap suatu barang ataupun jasa. Perkembangan bisnis e-commerce telah meningkat dengan tajam di Indonesia, diperkirakan sebanyak 7,4 juta orang berbelanja online pada tahun 2015 . Produsen ditantang untuk dapat menjawab pertanyaan dari konsumen apakah bauran pemasarannya dapat selalu mencerminkan tren terbaru. Produsen diharapkan dapat selalu melalukan check-in sebelum mereka check-out pada bisnis e-commerce sehingga produsen dapat melihat bagaimana bisnis e-commerce ini dapat memenuhi keinginan Net
Gener sebagai konsumen dan melakukan transaksi.

Karakteristik pembeli online di Indonesia dalam memanfaatkan $e$ commerce (transaksi komersial yang dilakukan secara elektronik di Internet) cukup beragam, sebesar $58 \%$ konsumen membandingkan produk, harga dan fitur, $54 \%$ mencoba untuk memukan merk produk yang relevan, $22 \%$ Mencari pendapat dan ulasan seputar produk yang diinginkan, $19 \%$ Memeriksa ketersediaan produk dan mencari tempat untuk membeli, $19 \%$ konsumen memanfaatkan $e$ commerce untuk mendapatkan ide dan inspirasi. Net Gener terbagi menjadi dua yaitu Early Adopter (mereka yang mendapatkan produk dengan teknik terbaru sebelum kebanyakan orang mendapatkannya), dan Bleeding Edger (orang pertama yang mendapatkan produk dengan teknik terbaru). Colby Fede CEO 
Wiremedia, mengemukakan bahwa situs-situs blog dan jaringan sosial untuk meningkatkan pemasaran kepada sebuah merk yang sedang “...potensi viral marketing sangat berkembang”. besar yang dapat diberikan oleh

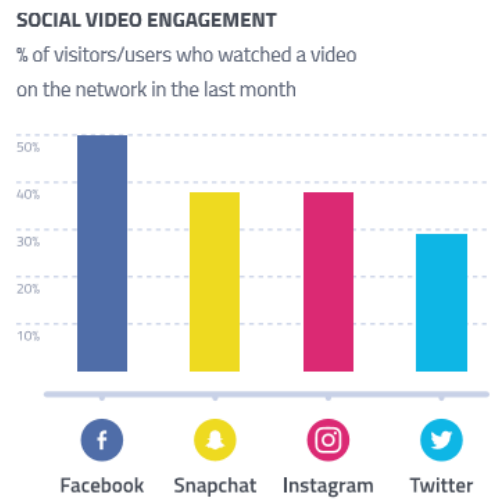

Gambar 8. Social Video Engagement

Source: GlobalWebIndex Q3 2016 | Base: Internet Users aged 16-64

Mander (2015) mengemukakan data dari Global Web Index bahwa seiring dengan koneksi mobile yang terus berkembang internet bergerak meraih pangsa online, dan konsumen saat ini lebih tertarik untuk melihat konten dalam bentuk audio visual. Berdasarkan data di atas dapat dilihat bahwa empat media sosial populer dan tingkat social video engagement memposisikan Facebook diurutan tertinggi. Facebook yang sebelumnya tidak mengelola konten video saat ini mulai menggencarkan konten videonya sebagai salah satu langkah cerdas dari jaringan sosial terbesar di dunia ini. Lebih dari separuh Facebookers menonton video yang ditampilkan, hal ini menunjukkan adanya tingkat keterlibatan yang lebih luas yang telah diperoleh sebagai hasil dari inovasi konten video yang dikelola oleh Zuckerberg \& Co. Meskipun kualitas jaringan videonya mungkin belum dapat menyaingi YouTube. Berbagi video adalah metrik yang saat ini diminati oleh Net Gener sebagai prosumer, berbagai fitur hosting streaming langsung dengan cepat menjadi pengembangan yang diperlukan untuk semua jaringan sosial media.

Berdasarkan riset GWI Sebanyak $93 \%$ pengguna internet menonton video online setiap bulannya. Konsumsi konten video meningkat lebih jauh seiring dengan peningkatan kualitas smartphone dengan cakupan 4G yang semakin memperluas kemampuan konsumen untuk menonton video kapanpun dan dimanapun mereka inginkan. 
YouTube, dan jaringan media sosial lainnya, telah menjadi penerima manfaat utama dari ledakan video online ini (sekitar 90\% Net Gener mengunjungi YouTube setiap bulannya). Permintaan besar dari Net Gener adalah peningkatan platform yang dapat memudahkan mereka dalam meng-hosting video buatan Net Gener amatir atau profesional. Setiap platform yang tampil dalam kegiatan digital sehari-hari Net Gener bisa mendapatkan keuntungan dari hosting video.

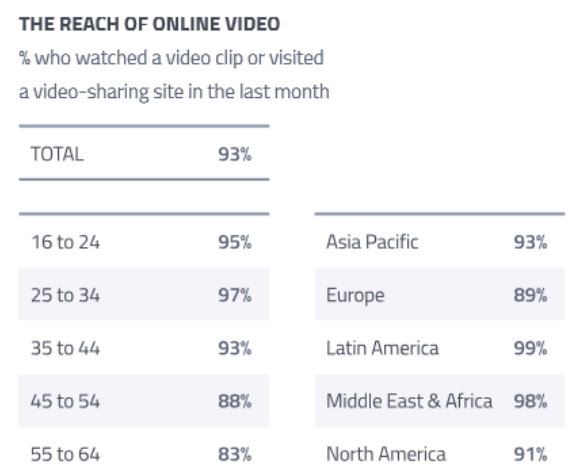

Gambar 9. The Reach of Online Video

Source: GlobalWebIndex Q3 2016 | Base: Internet Users aged 16-64

Ledakan konten video menghadirkan peluang yang sangat menarik. Seperempat konsumen digital mengatakan bahwa mereka menonton video bermerk, dan video adalah media yang dapat menawarkan satu solusi potensial untuk menumbuhkan ancaman pemblokiran terhadap tayangan iklan (baik melalui konten bermerk atau penempatan produk). Ketika platform berbagi video menjadi hal yang biasa dilakukan oleh Net Gener dengan perilaku prosumer, maka dapat menarik investasi besar. Meskipun video bukan satu-satunya jurus ampuh untuk seluruh tantangan yang dihadapi industri pemasaran digital, atau solusi untuk setiap masalah pertumbuhan platform, namun jelas perkembangan menunjukkan bahwa kita bergerak maju menuju lanskap video.

\section{SIMPULAN}

Perkembangan teknologi dan komunikasi mengikuti pula gaya hidup konsumen yang semakin virtual dan digital. Gaya hidup digital yang tumbuh seiring dengan konsep determinisme teknologi, memberikan kontribusi meningkatnya penggunaan internet dalam melakukan transaksi bisnise-commerce. Vloggers dan konsumen berada pada global village 
dan virtual market placemelalui bantuan media internet sebagai perpanjangan dari inderawi manusia (extention of man). Pengaruh dari vlogging network, penggabungan teknologi dalam komunikasi pemasaran yang diterapkan oleh produsen di era Net Generation juga sangat di dukung dengan aplikasi konsep komunikasi pemasaran era $e$ commerce hingga berpengaruh pula pada munculnya gaya hidup mencari informasi via platform online.

$$
\text { Vlogging membutuhkan }
$$

setidaknya pemrosesan informasi yang benar agar proses komunikasinya dapat berhasil. Vlogger melibatkan audiens mereka dengan memicu audiensnya agar partisipatif. Beberapa strategi yang diterapkan oleh vlogger diantaranya adalah "konten linguistik" atau kategori lingkungan fisik yang cenderung jauh lebih berhasil untuk meraih sejumlah komentar dari Followers maupun viewers. Dengan mengakses vlogging di media sosial, Net Gener dapat dengan cepat dan mudah mengakses konten buatan dari Net Gener lainnya yang sering menyertakan ulasan dan informasi produk.

Pendapat konsumen di era Net Gener, bisa dipengaruhi oleh beragam tokoh di media termasuk vloggers. Hal yang perlu diperhatikan bagi pebisnis $e$ commerce adalah mengoptimalkan fitur review produk pada online marketplace. Sehingga konsumen dapat melihat atau mengetahui rekomendasi dari konsumen lain, dan sebagai tantangan bagi penyedia layanan untuk semakin mengoptimalkan produknya. Para Manajer bisnis e-commerce harus mempertimbangkan juru bicara yang digunakan untuk mempromosikan merk mereka, apakah menggunakan model berbayar, selebriti, atau vlogger, karena konsumen kecenderungannya adalah ingin menemukan kesamaan dari kebutuhannya dengan yang disampaikan oleh konten promosi di media. Media sosial khususnya vlogging network dapat menjadi alat penting bagi para produsen $e$ commerce untuk promosi produk dan menjalin hubungan dengan konsumen mereka yaitu para Net Gener.

Vlogging Network semakin diminati karena keputusan pembelian konsumen e-commerce dengan cepat dipengaruhi oleh media sosial, dan pengalaman rekan-rekan mereka. Blogger dan vloggers adalah sumber pengalaman pribadi yang terpercaya, dengan tampilan video mereka yang dapat menutup celah antara merk dan konsumen menjadi inovasi dalam penyajian konten advertorial. Review produk yang di sampaikan oleh para vlogger dapat membantu konsumen menggali informasi lebih dalam, karena seringkali produk di marketplace spesifikasinya kurang 
jelas dan detail. Pihak produsen seharusnya mendorong seluruh info agar bermanfaat bagi konsumen dan dapat meningkatkan penjualan. Pelayanan yang bagus dan terstandarisasi dengan baik akan membuat Net Gener sebagai konsumen merasa nyaman dalam bertransaksi melalui e-commerce. Jika seorang konsumen memberikan review kurang baik terhadap suatu produk maka akan mempengaruhi persepsi konsumen lain yang membaca review produk tersebut. Sinergi dengan jaringan vlogging dapat membantu produsen dalam meningkatkan pemasaran dan pelayanan produk kepada konsumen.

\section{UCAPAN TERIMAKASIH}

Terimakasih atas dukungan dan dana penelitian dari SEAMEO (Science and Education for Agriculture and Development) SEARCA (Southeast Asian Regional Center for Graduate Study and Research In Agriculture). Terimakasih kepada Bapak Dr. Djuara P Lubis.

\section{DAFTAR PUSTAKA}

Alwin, D. F., McCammon, R. J. (2003). Generations, Cohorts, and Social Change. Handbook of the Life Course, 23-49.

Bolton, R. N., Parasuraman, A., Hoefnagels, A., Migchels, N., Kabadayi, S., Gruber, T., Leureiro, Y. K., Solnet, D.
(2012).

Understanding

Generation Y And Their Use Of Social Media: A Review And Research Agenda. Journal Of Service Management, 24, 245267.

Dredge, Stuart. (2015).

https://www.theguardian.com/tech nol ogy/2015/feb/05/youtubevloggers-popular-study-influence, diakses pada 7 Juni 2017, pukul 12.23 WIB.

Ecommerceiq. (2017). https://ecommerceiq.asia/topecommerce-sites-indonesia/, diakses pada 9 Juni 2017, pukul 12.19 WIB.

Frobenius, M. (2014). Audience Design In Monologues: How Vloggers Involve Their Viewers. Journal of Pragmatics, 72, 5972.

Harley, D., Fitzpatrick, G. (2009). Creating A Conversational Context Through Video Blogging: A Case Study of Geriatric 1927. Journal Computers In Human Behavior, 25, 670-689.

Lee, J.E., Watkins, B. (2016). YouTube Vloggers Influence on Consumer Luxury Brand Perceptions and Intentions. Journal of Business Research, 69, 5753-5760.

Mander, Jason. (2015). http://blog.globalwebindex.net/c hart-of-the-day/16-34s-lead-the- 
vlogging-trend/, diakses pada 7

Juni 2017, pukul 13.46 WIB.

Prensky, M. (2001). Digital Natives,

Digital Immigrants. Journal

From on theHorizon (MCB

University Press), 9, 1-6.

Rogers, E. M., Kincaid, D. L. (1981).

Communication Networks:

Toward a New Paradigm for

Research. New York: The Free

Press.

Sari, Intan Kemala. (2016).

https://wolipop.detik.com/read/20

16/07/29/170926/3264586/234/st

rategi-promosi-yang-dijalankan-

pebisnis-kosmetik-online-lokal,

diakses pada 9 Juni 2017, pukul 14.56 WIB.

Scoot. (2000). Social Network

Analysis: A Handbook Second

Edition. California (US): SAGE

Publications. Inc.

Stiggants, Ryan. (2015).

http://www.zeta.net/vlog-online-

marketing/, diakses pada 7 Juni

2017 pukul 12.23 WIB.

Tapscott, D. (2013). Grown Up

Digital yang Muda yang Mengubah Dunia. Jakarta: PT.

Gramedia Pustaka Utama.

Tham, J. (2014). Defining Media convergence. United State: St.

Cloud State University.

Wolipop.(2017).https://wolipop.detik

.com/thespotlight/vloggerinspira

tif/8430/abel-cantika, diakses

pada 9 juni 2017, pukul 14.56

WIB). 